\title{
Colostrum supplementation with n-3 fatty acids and a-tocopherol alters plasma polyunsaturated fatty acid profile and decreases an indicator of oxidative stress in newborn calves
}

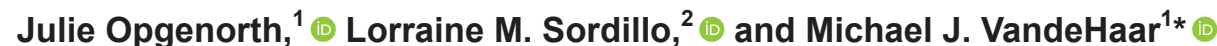 \\ ${ }^{1}$ Department of Animal Science, Michigan State University, East Lansing 48824 \\ ${ }^{2}$ Department of Large Animal Clinical Sciences, Michigan State University, East Lansing 48824
}

\section{ABSTRACT}

Our objective was to characterize the effects of supplementing newborn calves with n-3 fatty acids (FA) and $\alpha$-tocopherol on blood lipid profiles and oxidant status in early life. Sixteen calves received 0 or $60 \mathrm{~mL}$ of 1:1 fish and flaxseed oil with $200 \mathrm{mg}$ of $\alpha$-tocopherol in $2.8 \mathrm{~L}$ of colostrum within $6 \mathrm{~h}$ after birth. Colostrum was $>22 \%$ on the Brix scale. Blood was sampled on d 1, $2,4,7,14$, and 21 after birth for assessment of plasma polyunsaturated FA, $\alpha$-tocopherol, total serum protein, and oxidant status index, an indirect indicator of oxidative stress that examines the balance between the concentration of reactive oxygen and nitrogen species and antioxidant capacity in serum. Health was observed daily. Weight and hip height were recorded at birth, 3 wk, and 8 wk. Data were analyzed with a Mixed procedure of SAS 9.4 (SAS Institute Inc., Cary, NC). Treatment did not alter concentration of total protein in blood serum, prevalence of diarrhea or other signs of disease, or rate of growth. Feeding n-3 FA and $\alpha$-tocopherol increased plasma concentrations of the n-3 FA, including $\alpha$-linolenic, eicosapentaenoic, and docosahexaenoic acids, with a concomitant decrease in oxidant status index during the first week of life. Concentrations of $\alpha$-tocopherol decreased with supplementation, but all calves maintained adequate concentrations. Oxidant status index of treated calves returned to the level of control calves by d 14 . We conclude that a colostrum supplement of n-3 FA and $\alpha$-tocopherol is safe to administer to newborn calves, reduces oxidant status in the first week of life, and may improve health and performance.

Key words: oxidative stress, neonatal health, colostrum, n-3 fatty acid, dairy calf

Received August 1, 2019.

Accepted November 16, 2019.

*Corresponding author: mikevh@msu.edu

\section{INTRODUCTION}

Calves are especially vulnerable in the days following birth, due in part to physiological stress at birth and suboptimal immunocompetence (Murray and Leslie, 2013). Maternal stress in late gestation, onset of oxygen respiration, and dystocia can plague newborn calves by instigating oxidative stress and a prolonged state of inflammation (Saugstad, 2003; Hulbert and Moisá, 2016; Ling et al., 2018). In fact, this major stress period has been called the "birth critical window" (Hulbert and Moisá, 2016). Our long-term goal is to improve health of calves in the first 2 wk of life without the use of antibiotics to enhance feed efficiency and growth.

In cattle, daily dietary supplements of n-3 fatty acids (FA) have been recognized for their influence on health (Moallem, 2018), inflammation, and oxidative stress (Mavangira and Sordillo, 2018). Previous studies indicate that n-3 FA supplementation to milk replacer improved growth, health, or indicators of immune function in calves (Ballou et al., 2008; Ballou and DePeters, 2008; Karcher et al., 2014). This is accomplished in part by production of anti-inflammatory n-3 FA metabolites coupled with antioxidant properties (Mavangira and Sordillo, 2018). Feeding diets that enhance growth rates during the preweaning period affects age of first service, conception, and first-lactation milk yield (Brown et al., 2005; Davis Rincker et al., 2011). All preweaned calf studies involving n-3 FA supplementation to date have relied on milk replacer or calf starter as the vehicle, but to our knowledge none supplemented these FA to colostrum in a one-time dose. Such a burst in supplemental n-3 FA could boost blood n-3 FA and mitigate oxidative stress experienced in the first $2 \mathrm{wk}$ of life.

Increasing plasma PUFA concentrations in young calves was previously attempted through supplementing prepartum dams, but results indicate that placental selectivity of FA is regulated beyond additional dietary modifications (Garcia et al., 2014). Mixed results are reported on the ability of maternal colostrum to mirror an increase in prepartum PUFA dietary intake (Leiber 
et al., 2011; Jolazadeh et al., 2019). Thus, we chose to supplement maternal colostrum directly with n-3 FAenriched oils instead of relying on late-gestation dam supplementation.

Our hypothesis was that supplementing maternal colostrum directly with $60 \mathrm{~mL}$ of a blend of fish and flaxseed oils rich in n-3 FA and $\alpha$-tocopherol, often included with PUFA supplementation, would increase plasma concentrations of n-3 FA and decrease oxidant status index (OSi; an indicator of oxidative stress in the days following birth) to potentially improve calf health and growth during the first 3 wk of life. However, if added n-3 FA hinder absorption of nutrients or immunoglobulins in colostrum, mortality and morbidity rates may increase. Our specific aim was to conduct a study focused on monitoring health, passive transfer, indicators of oxidative stress, and n-3 FA plasma concentrations following colostrum n-3 FA supplementation during the first week of life.

\section{MATERIALS AND METHODS}

\section{Experiment Design}

The study was conducted from March to May 2018 at the Michigan State University Dairy Teaching and Research Center (East Lansing) and was approved by the Institutional Care and Use Committee (approval no. 03/18-035-00). Outside temperature averaged $12.5^{\circ} \mathrm{C}$. Throughout the course of the study, the maximum temperature reported was $30^{\circ} \mathrm{C}$ and the minimum was $-10^{\circ} \mathrm{C}$.

Sixteen calves ( 8 bulls and 8 heifers) were blocked by sex and randomly assigned to control or treatment groups at birth. The ratio of calves born from multiparous cows to those born from primiparous cows was the same. Control $(\mathbf{C O N})$ calves received $2.8 \mathrm{~L}$ of maternal colostrum within $6 \mathrm{~h}$ after birth without any additional supplementation. Treatment (FFE) calves received colostrum supplemented with $60 \mathrm{~mL}$ of a 1:1 mixture of fish and flaxseed oils and $200 \mathrm{mg}$ (134 IU) of $\alpha$-tocopherol oil. Additionally, the supplement included $12 \mathrm{~mL}$ of Tween 80 to function as an emulsifier by incorporating the hydrophobic n-3 FA-enriched oils into the colostrum suspension and to facilitate FA absorption. Colostrum was not pooled and CON calves received no placebo supplementation, so treatments were not isocaloric.

All colostrum was from dams at the Michigan State University dairy that had met quality standards $(>50$ $\mathrm{g}$ of immunoglobulin/L). Colostrum was stored frozen, and servings were retrieved at random as calves were born and sampled for PUFA analysis (Table 1). Calves were bottle fed unless esophageal tube feeding
Table 1. Least squares means of PUFA concentrations (nM) in randomly assigned maternal colostrum of first feeding before FFE supplementation

\begin{tabular}{lccc}
\hline & \multicolumn{2}{c}{ Treatment $^{1}$} & \\
\cline { 2 - 3 } Colostrum & CON & FFE & \multirow{2}{*}{ SEM } \\
\hline PUFA & 352 & 261 & 57.1 \\
C18:2n-6 & 22.9 & 20.9 & 3.53 \\
C18:3n-3 & 41.9 & 26.6 & 27.9 \\
C20:3n-6 & 110 & 72.6 & 22.1 \\
C20:4n-6 & 17.5 & 17.7 & 2.94 \\
C20:5n-3 & 32.3 & 17.2 & 8.60 \\
C22:4n-6 & 111 & 93.5 & 12.8 \\
C22:5n-3 & 1.68 & 2.27 & 0.396 \\
C22:6n-3 & & & \\
\hline
\end{tabular}

${ }^{1} \mathrm{CON}=$ control (no supplement added to colostrum); FFE $=60 \mathrm{~mL}$ of a 1:1 fish oil:flaxseed oil blend with $200 \mathrm{mg}$ of $\alpha$-tocopherol added to colostrum.

was necessary. After colostrum feeding, calves received a bovine rotavirus and coronavirus prevention vaccine and intramuscular injections of $1 \mathrm{~mL}$ of vitamins $\mathrm{A}$ and $\mathrm{D}, 200 \mathrm{mg}$ of $\alpha$-tocopherol, and $2 \mathrm{mg}$ of selenium. All calves at 12 to $18 \mathrm{~h}$ after birth received a second feeding of $1.9 \mathrm{~L}$ of colostrum without supplementation.

Calves were housed outside following their first day of life in individual calf hutches bedded with straw and had no physical contact with other calves. They were provided with access to water and calf starter grain ad libitum and fed with milk replacer at 0900, 1600, and 2100 h. Table 2 shows the Land O' Lakes (Arden Hills, MI) Cow's Match Cold Front milk replacer composition according to the manufacturer's specifications. Table 3 lists the feeding schedule and amounts fed. Calves were then followed for $3 \mathrm{wk}$ after birth for assessment of health indicators and growth.

Weights and hip heights were measured on $\mathrm{d} 1,7$ $( \pm 1), 14( \pm 1)$, and $21( \pm 1)$ of age. Before weaning at $8 \mathrm{wk}$, calves were again weighed to monitor ADG during the preweaning period. Calves were observed daily before the morning milk replacer feeding to visually score feces, eyes, nose, and ears to assess general health. Health scoring was based on the University of

Table 2. Composition (air-dry basis) of Cow's Match Cold Front milk replacer (Land O' Lakes, Arden Hills, MI) fed to calves during the preweaning period according to the manufacturer's specifications

\begin{tabular}{ll}
\hline Item & Value \\
\hline $\mathrm{CP}$ & Not less than $28 \%$ \\
Crude fat & Not less than $10 \%$ \\
Crude fiber & Not more than $0.20 \%$ \\
Calcium & Not less than $0.75 \%$ or more than $1.25 \%$ \\
Sodium & Not more than $1.20 \%$ \\
Phosphorus & Not less than $0.70 \%$ \\
Vitamin A & Not less than $9,072 \mathrm{IU} / \mathrm{kg}$ \\
Vitamin $\mathrm{D}_{3}$ & Not less than $2,268 \mathrm{IU} / \mathrm{kg}$ \\
Vitamin E & Not less than $68 \mathrm{IU} / \mathrm{kg}$ \\
\hline
\end{tabular}


Table 3. Milk replacer ${ }^{1}$ feeding schedule (L/feeding) of all calves in the study starting at $d 1$ of age

\begin{tabular}{lccc}
\hline & \multicolumn{3}{c}{ Feeding } \\
\cline { 2 - 4 } Calf age (wk) & $0900 \mathrm{~h}$ & $1600 \mathrm{~h}$ & $2100 \mathrm{~h}$ \\
\hline $0-1$ & 2.4 & 2.4 & 2.8 \\
$1-6$ & 2.8 & 2.8 & 3.8 \\
$6-8$ & 3.8 & 0 & 0 \\
\hline
\end{tabular}

${ }^{1}$ Each liter contained $0.13 \mathrm{~kg}$ of milk replacer powder.

Wisconsin-Madison's calf health scoring chart (https: //www.vetmed.wisc.edu/dms/fapm/fapmtools/8calf/ calf_health_scoring_chart.pdf).

\section{Sample Collection}

Blood was collected from the jugular vein of calves on d 1 ( $24 \pm 4 \mathrm{~h}), 2(48 \pm 4 \mathrm{~h}), 4( \pm 1 \mathrm{~d}), 7$ ( $\pm 1 \mathrm{~d})$, $14( \pm 2 \mathrm{~d})$, and $21( \pm 2 \mathrm{~d})$ after birth in 2 tubes containing serum separator or EDTA. Serum and plasma were collected after centrifugation at $1,700 \times g$ for 15 min at $4^{\circ} \mathrm{C}$. Plasma collected from EDTA tubes after centrifugation was stored at $-20^{\circ} \mathrm{C}$ before $\mathrm{FA}$ analysis. Serum aliquots designated for oxidant status assessment were immediately flash frozen in liquid nitrogen and transported in dry ice before storing at $-80^{\circ} \mathrm{C}$. Remaining serum was tested with a digital Brix refractometer for serum total protein concentrations and stored at $-20^{\circ} \mathrm{C}$. Colostrum was sampled from each calf's first feeding and stored at $-20^{\circ} \mathrm{C}$. Frozen serum and collected colostrum samples were shipped to Saskatoon Colostrum Company (Saskatoon, SK, Canada) for further analysis of immunoglobulin concentrations with radial immunodiffusion. Colostrum was also assessed for PUFA composition using liquid chromatographyMS quantification after hydrolysis and FA solid-phase extraction. Plasma concentrations of $\alpha$-tocopherol were analyzed using ultra-performance liquid chromatography by the Michigan State University Veterinary Diagnostics Laboratory (East Lansing).

\section{Colostrum PUFA Analysis}

An antioxidant-reducing agent of $50 \%$ methanol, $25 \%$ ethanol, and $25 \%$ water with $0.9 \mathrm{mM}$ butylhydroxytoluene, $0.54 \mathrm{~m} M$ EDTA, $3.2 \mathrm{~m} M$ triphenylphosphine, and $5.6 \mathrm{mM}$ indomethacin, as described in Kuhn et al. (2018), was added at $20 \mu \mathrm{L}$ to $125 \mu \mathrm{L}$ of thawed colostrum. Samples underwent lipid hydrolysis via the addition of $178 \mu \mathrm{L}$ of $\mathrm{KOH}$ and incubating for $45 \mathrm{~min}$ at $45^{\circ} \mathrm{C}$. Once samples cooled to room temperature, they were centrifuged at $4,800 \times g$ for $10 \mathrm{~min}$ at $4^{\circ} \mathrm{C}$. Then, $6 \mathrm{M} \mathrm{HCl}$ was added to the removed supernatant in increments of $10 \mu \mathrm{L}$ until the supernatant $\mathrm{pH}$ was decreased to 4 or less. An internal standard mixture of $15 \mu \mathrm{L}$ was added before undergoing solid-phase extraction with Oasis HLB $12-\mathrm{cm}^{3}$ LP extraction columns (Waters, Milford, MA) via a Biotage (Charlotte, NC) ExtraHera, further described in Kuhn et al. (2018). Samples were then dried in a Savant SpeedVac (Thermo Fisher Scientific, Waltham, MA) and reconstituted in 1.5:1 methanol:HPLC water. After filtration, samples were placed in glass vials with inserts and stored at $-20^{\circ} \mathrm{C}$ until liquid chromatography-MS analysis.

\section{Plasma PUFA Analysis}

Extraction and analysis of plasma PUFA followed methods modified from Mavangira et al. (2015). In brief, $1 \mathrm{~mL}$ of plasma was thawed on ice and $1 \mathrm{~mL}$ of $4 \%$ formic acid and $4 \mu \mathrm{L} / \mathrm{mL}$ of an antioxidant-reducing agent to protect samples from lipid peroxidation during processing (O'Donnell et al., 2008) were added to the plasma. A mixture of internal standards $(15 \mu \mathrm{L})$ was added to each sample mixture as well, consisting of 0.25 $\mu M 5(\mathrm{~S})$-HETE- $d_{8}, 0.25 \mu M$ 15(S)-HETE- $d_{8}, 0.5 \mu M$ 8(9)-EET- $d_{11}, 0.5 \mu M \mathrm{PGE}_{2}-d_{9}$, and $0.25 \mu M 8,9$-DHET$d_{11}$. Waters Oasis Prime HLB $3-\mathrm{cm}^{3}$ solid-phase extraction columns were used for solid-phase extraction, which was performed using Biotage ExtraHera. After samples were loaded onto columns and excess infranatant was discarded with nitrogen, columns were washed with $3 \mathrm{~mL}$ of $5 \%$ methanol and then $2.5 \mathrm{~mL}$ of $90: 10$ acetonitrile:methanol eluted samples. Leftover solvents were evaporated with a Savant SpeedVac. A mixture of 1.5:1 methanol:HPLC water brought the PUFA back into solution before filtering and dispensing into glass chromatography vials with inserts. Vials were stored at $-20^{\circ} \mathrm{C}$ until analysis with liquid chromatography-MS. A 6-point standard curve was used with the internal standards previously mentioned for quantification of PUFA concentrations.

\section{OSi}

Oxidant status, an indirect indicator of oxidative stress, was assessed with 2 separate assays and calculated as a ratio of reactive oxygen and nitrogen species (RONS) to antioxidant capacity. The concentrative balance of RONS and antioxidants together may affect the potential for oxidative stress to occur, and as such, oxidant status requires the measurement of both effectors concurrently.

The RONS concentrations in serum were measured by counting the relative fluorescent units per microliter using the Cell Biolabs Inc. (San Diego, CA) Oxiselect 
in vitro ROS/RNS assay kit. Briefly, a fluorogenic probe is added to samples where free radicals react to form 2',7'-dichlorodihydrofluorescein diacetate, the fluorescence intensity of which can be related to the concentration of free radicals in the sample. Samples were then measured at 530-nm excitation and 480-nm emission where blank sample fluorescence was subtracted from sample value (Ling et al., 2018). Antioxidant potential of the same samples was quantified through the units of Trolox equivalents, a synthetic analog of $\alpha$-tocopherol, where values of antioxidant potential were compared using a photometric plate reader. 2,2'-Azinobis-3-ethylbenzothiazoline-6-sulfonic acid was used as a radical cation to be reduced by antioxidants. The reduction potential of each sample, compared as Trolox equivalents, was compared using a photometric plate reader. This decolorization assay is further described in Re et al. (1999). Both assays used to assess oxidant status are detailed further by Putman et al. (2018).

\section{Statistical Analysis}

Data were analyzed with a mixed-effects model using SAS 9.4 (SAS Institute Inc., Cary, NC). Fixed effects were sex, treatment, and repeated measure of day. Random effects were block within sex and calf within block, sex, and treatment. Differences in preweaning daily gains, health observations, and colostrum IgG count were analyzed with the $t$-test procedure in SAS 9.4 to compare treatment means. Normality was assumed if $P>0.05$ with the general linear model procedure's Bartlett test for homogeneity of variance. If a data set was not considered normal, the data were log-transformed and least squares means (LSM) were back-transformed to original units for interpretation of tables and figures. Standard errors (SE) of log-transformed data were calculated as follows:

$$
\begin{gathered}
\text { positive } \mathrm{SE}=10^{\text {(transformed LSM }+ \text { transformed SE) }} \\
- \text { back-transformed LSM; } \\
\text { negative SE }=\text { back-transformed LSM } \\
-10^{(\text {transformed LSM }- \text { transformed SE) }} .
\end{gathered}
$$

Differences in main effects were significant if $P \leq 0.05$ and tendencies if $0.05<P \leq 0.10$. Differences in interactions were significant if $P \leq 0.10$ and tendencies were reported if $0.10<P \leq 0.15$.

We tested for effects of ambient temperature and temperature swing during the first $3 \mathrm{~d}$ of age for each calf, and no differences were observed between $\mathrm{CON}$ and FFE $(P=0.56)$. Temperature swing did not influ- ence analysis of variables, so the effect of temperature was not included in the mixed model as a random factor. The percentage of calves from primiparous dams was similar for $\mathrm{CON}$ and $\mathrm{FFE}(P=0.64)$; likewise, parity was not considered necessary to include in the analysis.

\section{RESULTS}

\section{Health and Growth}

The FFE treatment did not alter the number of diarrheal medications given per calf during the first $3 \mathrm{wk}$ of life (1.3 and 2.3 for CON and FFE, respectively; $P$ $=0.18$ ). Calves maintained generally healthy dispositions across treatment groups, with CON averaging 1.4 diarrheal treatment per calf and FFE averaging 1.0 diarrheal remedy per calf $(P=0.59)$ in the first $3 \mathrm{wk}$ of life. By 3 wk of age, the average number of refusals, or incomplete milk replacer meals, per calf for each treatment group was 1.3 and 2.3 for $\mathrm{CON}$ and $\mathrm{FFE}$, respectively $(P=0.18)$.

Overall, calves were healthy with little incidence of disease in the first $3 \mathrm{wk}$ of life. Health scores did not differ between CON and FFE. On a scale of 0 to $3(0$ $=$ normal and $3=$ most unhealthy), FFE nasal scores tended to be lower $(P=0.07)$ than $\mathrm{CON}$ scores $(0.1$ and 0.4 , respectively).

Across all calf first feedings, IgG concentrations in colostrum were greater than $50 \mathrm{~g} / \mathrm{L}$, indicating that all calves received colostrum of acceptable antibody quality. Calf serum IgG concentrations during the first week of life were similar for CON and FFE (36 and $31 \mathrm{~g} / \mathrm{L}$, respectively). Apparent efficiency of $\operatorname{IgG}$ absorption was not different in CON and FFE as calculated using the Penn State colostrum calculator spreadsheet (Jones and Heinrichs, 2016). Colostrum and calf serum Brix readings were similar in feeding groups.

The FFE calves tended to have higher birth weights (46 kg) compared with CON calves $(42 \mathrm{~kg} ; P=0.09)$. Daily gains during individual wk 1,2 , and 3 of age did not differ $(P \geq 0.92)$. Overall, ADG from birth to 3 wk was not different $(P=0.55 ; 0.44$ and $0.39 \mathrm{~kg} / \mathrm{d}$ for CON and FFE, respectively), and growth was not different during the preweaning period from birth to 8 wk $(0.63$ and $0.55 \mathrm{~kg} / \mathrm{d}$ for CON and FFE, respectively; $P=0.35)$.

During the first week of life, all calves maintained average serum protein concentrations above $52 \mathrm{~g} / \mathrm{L}$. One calf had serum concentrations below $52 \mathrm{~g} / \mathrm{L}$ and experienced acute infection of the hindgut during the second week of life. Removal of this calf from the study did not influence results. 


\section{PUFA Profile and $\alpha$-Tocopherol in Plasma}

$n$-3 FA. The concentration of nonesterified docosahexaenoic acid (DHA) in plasma was increased $(P$ $=0.01$ ) during the first week after supplementation. Concentrations of eicosapentaenoic acid (EPA) and $\alpha$-linolenic acid (ALA) increased with FFE $(P<0.001)$ during the first week of life (Figure 1). Concentration of EPA was exacerbated $(P \leq 0.01)$ by the differences in treatment $\times$ day effect on $\mathrm{d} 1,2$, and 4 after birth. On d 7 after birth, FFE also tended $(P=0.09)$ to exhibit increased free EPA concentrations compared with CON.

n-6 FA. Flaxseed oil contains $16.5 \%$ linoleic acid, which is a precursor to proinflammatory arachidonic acid (ARA). The FFE treatment did not increase linoleic acid in plasma of FFE compared with $\mathrm{CON}$ $(P=0.18)$. However, FFE increased ARA and dihomo$\gamma$-linolenic acid during the first week of life $(P=0.03$ and $P=0.02$, respectively), both of which result from downstream metabolism of linoleic acid. The ratio of $n$ -6:n-3 FA over the same time period was decreased by FFE in the first week $(P<0.0001)$. This was especially true on sample d 1 and 2 of age with a strong treatment $\times$ day interaction $(P<0.002)$. Values are given in Table 4.

$\alpha$-Tocopherol. Concentrations of plasma $\alpha$-tocopherol during the first week of life were lower in FFE than in CON $(P=0.02)$. All calves maintained similar $\alpha$-tocopherol concentrations at $1 \mathrm{~d}$ of age, but FFE exhibited lower concentrations the following days in wk 1 . This change corresponded to increased n-3 FA concentrations during wk 1 (Figure 1).

\section{OSi}

Oxidant status index was decreased by FFE during the first week of life (Figure 2). Because OSi is determined by combining 2 separate assays, values are considered arbitrary units (AU). The CON treatment increased OSi values from 49 to $73 \mathrm{AU}$ from 1 to $2 \mathrm{~d}$ of age. The difference between CON OSi values on 4 and $7 \mathrm{~d}$ of age was even more evident, with an increase from 67 to 108 AU. The main effect of day in the model varied greatly $(P<0.001)$ as OSi increased over time.
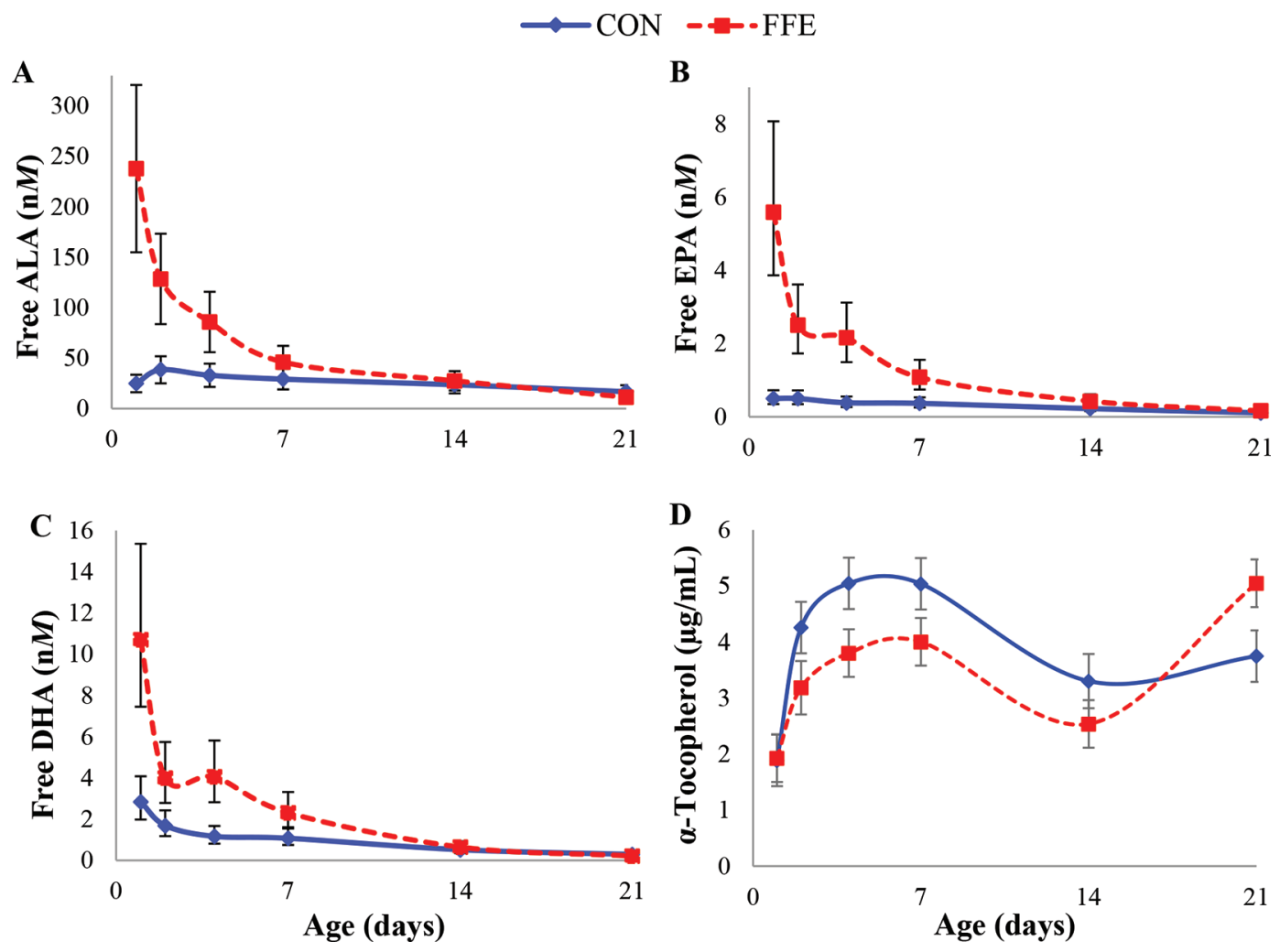

Figure 1. Changes in plasma concentrations of (A) $\alpha$-linolenic acid (ALA; $\mathrm{n} M)$, (B) eicosapentaenoic acid (EPA; $\mathrm{n} M)$, (C) docosahexaenoic acid (DHA; $\mathrm{n} M)$, and (D) plasma $\alpha$-tocopherol $(\mu \mathrm{g} / \mathrm{mL})$ as calf age increased. $\mathrm{CON}=$ control (no supplement added to colostrum); FFE $=60$ $\mathrm{mL}$ of a 1:1 fish oil:flaxseed oil blend with $200 \mathrm{mg}$ of $\alpha$-tocopherol added to colostrum. Fatty acid data are shown as LSM back-transformed from the model \pm SE. Calves given FFE had increased plasma n-3 fatty acid concentrations $(P \leq 0.01)$ and decreased $\alpha$-tocopherol concentrations $(P=0.02)$ during the first week of age. 
After the first week of life, OSi decreased to $76 \mathrm{AU}$ at $14 \mathrm{~d}$ and increased again to $92 \mathrm{AU}$ at $21 \mathrm{~d}$.

The OSi values for FFE generally exhibited greater stability with less fluctuation between days. Contrasting with CON, FFE decreased OSi values from 41 to 32 $\mathrm{AU}$ at 1 to $2 \mathrm{~d}$. The FFE OSi gradually increased from 32 to $79 \mathrm{AU}$ on 2 to $7 \mathrm{~d}$, but this increase was lower and gradual compared with CON. Furthermore, FFE OSi remained relatively constant from d 7 to 21 of age, with daily OSi means varying by only 8 AU. Overall, treatment $\times$ day effect was not different between $\mathrm{CON}$ and $\operatorname{FFE}(P=0.45)$.

The decreased OSi in FFE was not attributable to antioxidant potential in serum $(P=0.14)$. The average of treatments during the first week of life for $\mathrm{CON}$ and FFE was 6.5 and 7.1 Trolox equivalents, respectively. The concentration of RONS tended to decrease $(P=$ 0.08 ) in FFE calves (452 and 344 relative fluorescent units/ $\mu \mathrm{L}$ in $\mathrm{CON}$ and FFE, respectively).

\section{DISCUSSION}

This is the first study to show that a dietary supplement in colostrum containing n-3 FA and $\alpha$-tocopherol improves oxidant status and reduces the accumulation of RONS that is prevalent in newborn calves. The mechanism for this may be due to the altered ratio of free plasma n-6:n-3 FA of 23 with CON to 9 with FFE.

Newborns experience high levels of RONS production at birth through maternal oxidative stress in late gestation (Ling et al., 2018), placental preference for pro-RONS biomolecules (Braekke et al., 2006), and abrupt increase in oxygen exposure at birth (Frank, 1985). These contributing factors may lead to oxidative stress around birth when the calves' antioxidant capacity is inundated (Saugstad, 2003). Abuelo et al.
(2014) showed that OSi increased from birth to $6 \mathrm{~d}$ of age and suggested that this increase was possibly due to metabolic demands adapting to the extrauterine environment. Our results showed RONS concentrations in both CON and FFE calves $(P=0.02)$, and antioxidant capacity tended to decrease over the same time frame $(P=0.06)$, which confirmed that OSi increased during the first week of life. An increase in OSi occurred at 2 $\mathrm{d}$, but FFE delayed this increase.

Although FFE improved OSi during the first week of life compared with CON, OSi increased over the first week of life in all calves. Abuelo et al. (2014) found that OSi remained elevated compared with the first day of life at a consistent level from 6 to $29 \mathrm{~d}$ of age in calves. The current study sampled only to $21 \mathrm{~d}$ of age, but our data were consistent with past results. Oxidant status index has not been measured in previous studies supplementing milk replacer with n-3 FA. Therefore, a future experiment observing effects of OSi from n-3 FA supplementation in milk replacer may be of interest.

The mechanisms by which FFE decreased OSi resulted more from decreased RONS production $(P=$ $0.08)$ than from a large increase in antioxidant capacity $(P=0.14)$; however, in both cases, FFE averaged lower RONS and higher antioxidant capacity than CON, yielding a decreased OSi $(P<0.01)$. One possible mechanism is through increased n-3 FA, which compete for the same enzymatic reactions n- 6 FA use to produce a large variety of known proinflammatory metabolites (Sordillo, 2018). Cytochrome enzymes, for example, use both n-3 and n-6 FA as substrates but, with increasing concentrations of n-3 FA, will sometimes favor EPA over ARA as a substrate (Arnold et al., 2010). Notably, EPA and DHA produce oxylipids with anti-inflammatory properties and oxylipids with lower proinflammatory potential than the competing

Table 4. Least squares means of plasma PUFA concentrations (nM) on d 1, 2, 4, and 7 of age ${ }^{1}$

\begin{tabular}{|c|c|c|c|c|}
\hline \multirow[b]{2}{*}{ Plasma PUFA } & \multicolumn{2}{|c|}{ Treatment $^{2}$} & \multicolumn{2}{|c|}{$95 \% \mathrm{CI}$} \\
\hline & $\mathrm{CON}$ & $\mathrm{FFE}$ & $\mathrm{CON}$ & FFE \\
\hline $\mathrm{C} 18: 2 \mathrm{n}-6$ & 1,220 & 1,500 & $930-1,500$ & $1,190-1,760$ \\
\hline $\mathrm{C} 18: 3 \mathrm{n}-3^{* * *}$ & 30.9 & 96.5 & $23.2-41.1$ & $72.5-129$ \\
\hline $\mathrm{C} 20: 3 \mathrm{n}-6^{*}$ & 0.259 & 0.405 & $0.163-1.43$ & $0.309-1.65$ \\
\hline $\mathrm{C} 20: 4 \mathrm{n}-6^{*}$ & 3.97 & 5.75 & $2.62-5.33$ & $4.40-7.10$ \\
\hline $\mathrm{C} 20: 5 \mathrm{n}-3^{* * *}$ & 0.434 & 2.39 & $0.222-0.847$ & $1.22-4.66$ \\
\hline C22:4n-6 & 0.0235 & 0.0263 & $0.015-0.037$ & $0.017-0.041$ \\
\hline C22:5n-3† & 1.46 & 1.98 & $0.914-2.01$ & $1.43-2.53$ \\
\hline $\mathrm{C} 22: 6 \mathrm{n}-3^{* *}$ & 1.8 & 4.5 & $0.977-2.50$ & $2.79-7.16$ \\
\hline 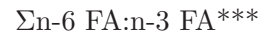 & 20.5 & 8.85 & $15.7-26.8$ & $6.80-11.5$ \\
\hline
\end{tabular}



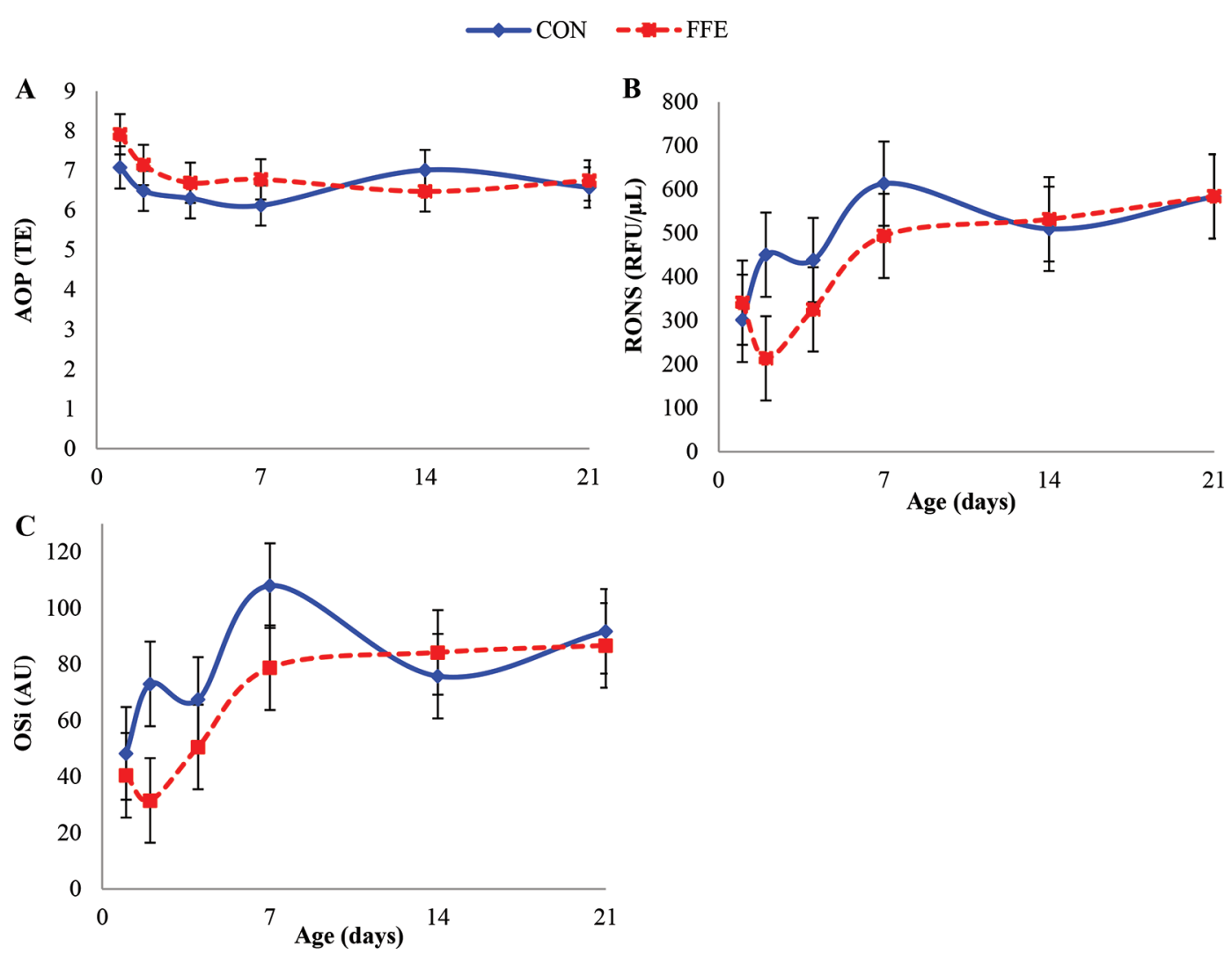

Figure 2. Changes in (A) antioxidant potential (AOP), (B) reactive oxygen and nitrogen species (RONS), and (C) oxidant status index (OSi) as calf age increased, given in Trolox equivalents (TE), relative fluorescent units (RFU) per microliter, and arbitrary units (AU), respectively. $\mathrm{CON}=$ control (no supplement added to colostrum); FFE $=60 \mathrm{~mL}$ of a 1:1 fish oil:flaxseed oil blend with $200 \mathrm{mg}$ of $\alpha$-tocopherol added to colostrum. Data are shown as LSM \pm SE predicted from the model. During the first week of age, FFE did not alter antioxidant potential $(P=$ $0.14)$ and tended to decrease RONS $(P=0.08)$. Overall, FFE decreased OSi in wk $1(P=0.01)$.

ARA substrate; subsequently, greater metabolism of EPA will result in decreased RONS production. Thus, a prolonged response in decreased oxidant status such as that observed may have been assisted by n-3 FA catabolism. Some metabolites such as resolvins and protectins act as anti-inflammatory signaling molecules and are not only effective at decreasing inflammation but also protect against hyperinflammatory conditions (Calder, 2010). A definitive association of downregulated inflammation with decreased RONS production has been observed after supplementation with n-3 FA (Takahashi et al., 2002). A future study should examine what products of n-3 FA metabolism may affect the oxidant balance after a one-time dose in colostrum as reported in the current study.

Our observation of decreased RONS production by the n-3 FA in FFE may have further improved with the addition of $200 \mathrm{mg}$ (334 IU) of $\alpha$-tocopherol, which was included to protect n-3 FA from peroxidation (Wang et al., 2010). In our study, we observed decreased $\alpha$-tocopherol concentrations in FFE calves during wk 1. Supplementation of PUFA is known to decrease $\alpha$-tocopherol concentrations in blood (Raederstorff et al., 2015), and we speculate that the depressed $\alpha$-tocopherol concentrations observed in FFE calves were due to depletion by n-3 FA to prevent peroxidation. Incorporating $200 \mathrm{mg}$ of $\alpha$-tocopherol in the FFE treatment, which is greater than the minimum recommendation of $0.6 \mathrm{mg}$ of $\alpha$-tocopherol/g of PUFA (Harris and Embree, 1963), was not enough to sustain plasma $\alpha$-tocopherol concentrations of FFE calves at the same concentrations as in CON calves; nevertheless, FFE calves did not show visible signs of $\alpha$-tocopherol deficiency, and plasma concentrations remained within recommended levels (Reddy et al., 1987).

We cannot discern whether n-3 FA alone, $\alpha$-tocopherol alone, or their combination was responsible for the decreased oxidant status of the FFE treatment. However, all calves received an intramuscular injection of $100 \mathrm{mg}$ of $\alpha$-tocopherol and $2 \mathrm{mg}$ of selenium at birth, and this supplement alone was unable to attenuate oxidative stress as much as the addition of FFE. The possibility 
that calves would benefit from additional antioxidants above $100 \mathrm{mg}$ of $\alpha$-tocopherol and $2 \mathrm{mg}$ of selenium should be explored.

Transfer of IgG from colostrum to calf is a primary mediator of calf disease resistance and resilience. Failure of passive transfer ( $<52 \mathrm{~g}$ of protein/L of serum) puts the calf at risk for poor vitality and immune function. To our knowledge, no one has published effects of a lipid supplement to colostrum. We found that FFE did not alter normal absorption of IgG. Serum protein concentrations remained similar across CON $(65 \mathrm{~g} / \mathrm{L})$ and FFE $(64 \mathrm{~g} / \mathrm{L})$, where $P=0.35$. Kamada et al. (2007) observed increased $\operatorname{IgG}$ concentrations in calves fed selenium-supplemented colostrum. Based on this finding, one might expect that the presence of $\alpha$-tocopherol in our supplement might also increase IgG concentrations, but we did not observe this.

\section{CONCLUSIONS}

A colostrum supplement of $60 \mathrm{~mL}$ of a 1:1 fish oil: flaxseed oil blend with $200 \mathrm{mg}$ of $\alpha$-tocopherol is safe to feed calves with no negative effects on passive transfer, growth, or indicators of health. The supplement increased plasma concentrations of ALA, EPA, and DHA, decreased the n-6:n-3 FA ratio in plasma, and decreased oxidant status index during the first week of life. We speculate that this change in n-6:n-3 FA ratio and decreased oxidant status may potentially improve health and growth.

\section{ACKNOWLEDGMENTS}

The authors thank the staff at the Michigan State University Dairy Cattle Teaching and Research Center (East Lansing), Saskatoon Colostrum Company (Saskatoon, SK, Canada) for analysis of immunoglobulin concentrations in colostrum and serum, and Michigan Alliance for Animal Agriculture (East Lansing) for financial support. The authors have not stated any conflicts of interest.

\section{REFERENCES}

Abuelo, Á., M. Pérez-Santos, J. Hernández, and C. Castillo. 2014. Effect of colostrum redox balance on the oxidative status of calves during the first 3 months of life and the relationship with passive immune acquisition. Vet. J. 199:295-299. https://doi.org/10.1016/ j.tvjl.2013.10.032.

Arnold, C., A. Konkel, R. Fischer, and W. Schunck. 2010. Cytochrome $\mathrm{P} 450$-dependent metabolism of $\omega-6$ and $\omega-3$ long-chain polyunsaturated fatty acids. Pharmacol. Rep. 62:536-547. https://doi.org/ 10.1016/S1734-1140(10)70311-X.

Ballou, M. A., G. Cruz, W. Pittroff, D. Keisler, and E. DePeters. 2008. Modifying the acute phase response of Jersey calves by supplementing milk replacer with omega-3 fatty acids from fish oil. J. Dairy Sci. 91:3478-3487. https://doi.org/10.3168/jds.2008-1016.
Ballou, M. A., and E. DePeters. 2008. Supplementing milk replacer with omega-3 fatty acids from fish oil on immunocompetence and health of Jersey calves. J. Dairy Sci. 91:3488-3500. https://doi .org $/ 10.3168 /$ jds.2008-1017.

Braekke, K., N. K. Harsem, and A. C. Staff. 2006. Oxidative stress and antioxidant status in fetal circulation in preeclampsia. Pediatr. Res. 60:560-564. https://doi.org/10.1203/01.pdr.0000242299 .01219.6a.

Brown, E. G., M. J. VandeHaar, K. M. Daniels, J. S. Liesman, L. T. Chapin, J. W. Forrest, R. M. Akers, R. E. Pearson, and M. S. W. Nielsen. 2005. Effect of increasing energy and protein intake on mammary development in heifer calves. J. Dairy Sci. 88:595-603. https://doi.org/10.3168/jds.S0022-0302(05)72723-5.

Calder, P. C. 2010. Omega-3 fatty acids and inflammatory processes. Nutrients 2:355-374. https://doi.org/10.3390/nu2030355.

Davis Rincker, L. E., M. VandeHaar, C. Wolf, J. Liesman, L. Chapin, and M. Weber Nielsen. 2011. Effect of intensified feeding of heifer calves on growth, pubertal age, calving age, milk yield, and economics. J. Dairy Sci. 94:3554-3567. https://doi.org/10.3168/jds .2010-3923.

Frank, L. 1985. Effects of oxygen on the newborn. Fed. Proc. 44:23282334 .

Garcia, M., L. Greco, M. Favoreto, R. Marsola, L. Martins, R. Bisinotto, J. H. Shin, A. L. Lock, E. Block, W. W. Thatcher, J. E. P. Santos, and C. R. Staples. 2014. Effect of supplementing fat to pregnant nonlactating cows on colostral fatty acid profile and passive immunity of the newborn calf. J. Dairy Sci. 97:392-405. https: //doi.org/10.3168/jds.2013-7086.

Harris, P. L., and N. D. Embree. 1963. Quantitative consideration of the effect of polyunsaturated fatty acid content of the diet upon the requirements for vitamin E. Am. J. Clin. Nutr. 13:385-392. https://doi.org/10.1093/ajcn/13.6.385.

Hulbert, L. E., and S. J. Moisá. 2016. Stress, immunity, and the management of calves. J. Dairy Sci. 99:3199-3216. https://doi.org/10 $.3168 /$ jds.2015-10198.

Jolazadeh, A. R., T. Mohammadabadi, M. Dehghan-Banadaky, M. Chaji, and M. Garcia. 2019. Effect of supplementing calcium salts of n-3 and n-6 fatty acid to pregnant nonlactating cows on colostrum composition, milk yield, and reproductive performance of dairy cows. Anim. Feed Sci. Technol. 247:127-140. https://doi .org/10.1016/j.anifeedsci.2018.11.010.

Jones, C., and J. Heinrichs. 2016. Trouble shooting colostrum management with the colostrum calculator Excel spreadsheet. Accessed Nov. 27, 2018. https://extension.psu.edu/trouble-shooting -colostrum-management-colostrum-calculator.

Kamada, H., I. Nonaka, Y. Ueda, and M. Murai. 2007. Selenium addition to colostrum increases immunoglobulin $\mathrm{G}$ absorption by newborn calves. J. Dairy Sci. 90:5665-5670. https://doi.org/10.3168/ jds.2007-0348.

Karcher, E. L., T. Hill, H. Bateman II, R. Schlotterbeck, N. Vito, L. Sordillo, and M. VandeHaar. 2014. Comparison of supplementation of n-3 fatty acids from fish and flax oil on cytokine gene expression and growth of milk-fed Holstein calves. J. Dairy Sci. 97:2329-2337. https://doi.org/10.3168/jds.2013-7160.

Kuhn, M. J., V. Mavangira, J. C. Gandy, and L. M. Sordillo. 2018. Production of $15-\mathrm{F}$-isoprostane as an assessment of oxidative stress in dairy cows at different stages of lactation. J. Dairy Sci. 101:9287-9295. https://doi.org/10.3168/jds.2018-14669.

Leiber, F., R. Hochstrasser, H. Wettstein, and M. Kreuzer. 2011. Feeding transition cows with oilseeds: Effects on fatty acid composition of adipose tissue, colostrum and milk. Livest. Sci. 138:1-12. https: //doi.org/10.1016/j.livsci.2010.11.016.

Ling, T., M. Hernandez-Jover, L. M. Sordillo, and A. Abuelo. 2018. Maternal late-gestation metabolic stress is associated with changes in immune and metabolic responses of dairy calves. J. Dairy Sci. 101:6568-6580. https://doi.org/10.3168/jds.2017-14038.

Mavangira, V., J. C. Gandy, C. Zhang, V. E. Ryman, A. Daniel Jones, and L. M. Sordillo. 2015. Polyunsaturated fatty acids influence differential biosynthesis of oxylipids and other lipid mediators during bovine coliform mastitis. J. Dairy Sci. 98:6202-6215. https://doi .org/10.3168/jds.2015-9570. 
Mavangira, V., and L. M. Sordillo. 2018. Role of lipid mediators in the regulation of oxidative stress and inflammatory responses in dairy cattle. Res. Vet. Sci. 116:4-14. https://doi.org/10.1016/j.rvsc.2017 .08 .002 .

Moallem, U. 2018. Invited review: Roles of dietary n-3 fatty acids in performance, milk fat composition, and reproductive and immune systems in dairy cattle. J. Dairy Sci. 101:8641-8661. https://doi .org/10.3168/jds.2018-14772.

Murray, C. F., and K. E. Leslie. 2013. Newborn calf vitality: Risk factors, characteristics, assessment, resulting outcomes and strategies for improvement. Vet. J. 198:322-328. https://doi.org/10.1016/j .tvjl.2013.06.007.

O'Donnell, V. B., B. Maskrey, and G. W. Taylor. 2008. Eicosanoids: Generation and detection in mammalian cells. Methods Mol. Biol. 462:1-19. https://doi.org/10.1007/978-1-60327-115-8_1.

Putman, A., J. Brown, J. Gandy, L. Wisnieski, and L. Sordillo. 2018. Changes in biomarkers of nutrient metabolism, inflammation, and oxidative stress in dairy cows during the transition into the early dry period. J. Dairy Sci. 101:9350-9359. https://doi.org/10.3168/ jds.2018-14591.

Raederstorff, D., A. Wyss, P. C. Calder, P. Weber, and M. Eggersdorfer. 2015. Vitamin $\mathrm{E}$ function and requirements in relation to PUFA. Br. J. Nutr. 114:1113-1122. https://doi.org/10.1017/ S000711451500272X

Re, R., N. Pellegrini, A. Proteggente, A. Pannala, M. Yang, and C. Rice-Evans. 1999. Antioxidant activity applying an improved ABTS radical cation decolorization assay. Free Radic. Biol. Med. 26:1231-1237. https://doi.org/10.1016/S0891-5849(98)00315-3.
Reddy, P. G., J. Morrill, and R. Frey. 1987. Vitamin E requirements of dairy calves. J. Dairy Sci. 70:123-129. https://doi.org/10.3168/jds .S0022-0302(87)79987-1.

Saugstad, O. D. 2003. Oxygen toxicity at birth: The pieces are put together. Pediatr. Res. 54:789. https://doi.org/10.1203/01.PDR $.0000103390 .01854 .0 \mathrm{E}$

Sordillo, L. M. 2018. Symposium review: Oxylipids and the regulation of bovine mammary inflammatory responses. J. Dairy Sci. 101:5629-5641. https://doi.org/10.3168/jds.2017-13855.

Takahashi, M., N. Tsuboyama-Kasaoka, T. Nakatani, M. Ishii, S. Tsutsumi, H. Aburatani, and O. Ezaki. 2002. Fish oil feeding alters liver gene expressions to defend against PPAR $\alpha$ activation and ROS production. Am. J. Physiol. Gastrointest. Liver Physiol. 282:G338-G348. https://doi.org/10.1152/ajpgi.00376.2001.

Wang, Y. M., J. H. Wang, C. Wang, B. Chen, J. X. Liu, H. Cao, F. C. Guo, and M. Vázquez-Añón. 2010. Effect of different rumen-inert fatty acids supplemented with a dietary antioxidant on performance and antioxidative status of early-lactation cows. J. Dairy Sci. 93:3738-3745. https://doi.org/10.3168/jds.2010-3054.

\section{ORCIDS}

Julie Opgenorth @ https://orcid.org/0000-0002-2271-4720

Lorraine M. Sordillo @ https://orcid.org/0000-0001-8873-3134

Michael J. VandeHaar @ https://orcid.org/0000-0002-8475-3493 